\title{
Midlife work ability and mobility limitation in old age among non-disability and disability retirees - a prospective study
}

Monika E. von Bonsdorff ${ }^{1} 2^{*}$, Taina Rantanen'1, Timo Törmäkangas' ${ }^{1}$, Jenni Kulmala, ${ }^{3,4}$, Timo Hinrichs ${ }^{5}$, Jorma Seitsamo ${ }^{6}$, Clas-Håkan Nygård ${ }^{7}$, Juhani IImarinen ${ }^{8}$ and Mikaela B. von Bonsdorff ${ }^{1,2}$

\begin{abstract}
Background: Little is known about the wellbeing and mobility limitation of older disability retirees. Personal and environmental factors, such as time spent in working life, may either exacerbate or mitigate the onset of mobility limitation in general population.

We aimed to study perceived midlife work ability as a determinant of self-reported mobility limitation in old age among municipal employees who transitioned into non-disability and disability retirement.

Methods: 4329 participants of the Finnish Longitudinal Study of Municipal Employees (FLAME) had retired during January 1985 and July 2000. They had data on retirement, perceived work ability in 1985, and self-reported mobility limitation (non-disability retirement $n=2870$, men $39 \%$; and diagnose-specific disability retirement $n=1459$, men $48 \%$ ). Self-reported mobility was measured in 1985, 1992, 1997 and 2009. The latest score available was used to assess the number of mobility limitation. Work ability was measured by asking the respondents to evaluate their current work ability against their lifetime best in 1985. Incidence rate ratios (IRRs) and $95 \%$ confidence intervals (Cls) for work ability predicting mobility limitation in non-disability and diagnose-specific disability retirement groups were calculated using Poisson regression models.
\end{abstract}

Results: The prevalence of mobility limitation for those who transitioned into non-disability retirement (Incidence Rate, IR $=0.45,95 \% \mathrm{Cl}=0.44-0.46)$ was lower compared to those who retired due to disability $(\mathrm{IR}=0.65, \mathrm{Cl}=0.63-0.66)$. A onepoint increase in the work ability score decreased the risk for having one more mobility limitation among non-disability and all diagnose-specific retirement groups (musculoskeletal disease, cardiovascular disease, mental disorder, and other diseases).

Conclusions: Better midlife work ability may protect from old age mobility limitation among those who retire due to non-disability and disability. Promoting work ability in midlife may lead to more independent, active aging, regardless of type of retirement.

Keywords: Work ability, Disability retirement, Mobility limitation, Aging, Municipal employees

\footnotetext{
* Correspondence: monika.bonsdorff@jyu.fi

${ }^{1}$ Gerontology Research Center and Department of Health Sciences, University

of Jyväskylä, PO Box 35, Jyväskylä, Finland

${ }^{2}$ Folkhälsan Research Center, Helsinki, Finland

Full list of author information is available at the end of the article
} 


\section{Background}

Optimal mobility, which can be defined as relative ease and freedom of movement in all of its forms, is a central part of healthy aging [1]. It has positive consequences both for the aging individual and their communities in terms of maintaining the ability to carry out tasks related to daily activities [2] and decreased need of health care services [1, 3]. The longitudinal paths leading to and thorough mobility limitation can be understood by using the disablement process model [4]. According to this model, functional limitation, such as mobility limitation, is preceded by 1) impairment in the form of dysfunctions in specific body systems caused by pathology, such as diseases or injuries, and 2) risk factors related to e.g. lifestyle, the environment or psychological factors.

Multifactorial causes, which underlie mobility limitation, include comorbidity [5], as well as other individual, lifestyle-, environment, behavioral, and social risk factors [6-10]. Furthermore, the link between midlife occupational physical activity [11], as well as work stress [12], and old age mobility limitation has been studied. Still, little is known about the role of working life and work history, along with possible work life exposures, even if it is plausible that personal and environmental factors, such as time spent in working life, may either exacerbate or mitigate the course and the nature of the disablement process [4]. Work ability, which is a central concept for older employees, indicates the balance between employees' resources and corresponding job demands [13, 14]. While this concept has to our knowledge not previously been linked with old age mobility limitation, individuals with poor work ability in midlife have higher risk of disability pension $[15,16]$, as well as old age disability and mortality [14].

The incidence of disability pension continues to be high in many European countries, despite improvements in health and increases in life expectancy in last decades [17]. Still, little is known about the life situation of individuals who were granted disability pension [18]. In 2013, 28 \% of Finnish retirees transitioned into disability retirement, mainly due to mental illnesses, musculoskeletal disorders and cardiovascular disease (CVD) [19]. Together with a high number of chronic diseases, excessive work strain not only predicts early exit from working life via disability retirement $[15,16]$, but may also be a risk factor for the onset of mobility limitation $[4,10]$ and subsequent loss of mobility in older age [5]. Preventing disability retirement, as well as maintaining the ability to function among individuals who are at high risk for mobility decline by identifying work-related factors that may decrease the prevalence of mobility limitation in older age, are of importance for the public health.

Our aim was to investigate longitudinally midlife work ability as a determinant of mobility limitation among municipal employees, who transitioned into nondisability or diagnose-specific disability retirement during the 28-year follow-up. Based on previous findings on mobility limitation [5] and old age health outcomes among disability retirees $[18,20,21]$, we expected primarily to find a higher incidence of old age mobility limitation among those who retired due to musculoskeletal disease or CVD, compared to non-disability retirees. As work ability is built on individuals' physical, psychological, and social resources [13], we expected better work ability to decrease the risk of subsequent mobility limitation among non-disability and even among disability retirees $[11,12]$.

\section{Methods}

\section{Participants}

Data come from the Finnish Longitudinal Study on $\mathrm{Mu}$ nicipal Employees (FLAME), conducted by the Finnish Institute of Occupational Health. At baseline in 1981, 6257 municipal sector employees aged 44-58-years working in various municipal occupations were randomly chosen from municipalities across Finland. They were followed up in 1985, 1992, 1997, and 2009 [14, 22]. The study, which focuses on work, health, and lifestyle factors, is on-going with register-based data on mortality available until end of July, 2009.

For the current study, we included all participants with data on work ability in 1985, type and date of formal retirement, along with self-reported information on postretirement mobility limitation. This left us with a sample of 4329 participants ( $42.1 \%$ men). Of the 1928 participants excluded from this study, 705 had no postretirement data available on mobility limitation, 18 died before retirement, 648 had missing data on retirement or disability retirement diagnose (due to e.g. migration before retirement), 410 on mobility limitation, and 147 on both retirement and mobility limitation. Compared to the effective sample in the current study, those with missing register data, were older, reported poorer work ability, were more often men, blue-collar (versus upper or lower white-collar) employees, not married, and reported more smoking and drinking, less physical activity, and more CVD, musculoskeletal, metabolic, and mental disease. This study was conducted among adult individuals with the approval of the Finnish Institute of Occupational Health Ethical Committee and conforms to the principles of the Declaration of Helsinki.

\section{Measures}

\section{Work ability}

Work ability was assessed in 1985, as a subjective evaluation of present work ability compared to lifetime best, with the question: 'Assume that your work ability at its best has a value of 10 points. What score would you give 
your current work ability?' This question is part of the seven-item Work Ability Index (WAI) [23] and has been found to capture most of the individual differences of the index [16]. WAI is accepted as a world-wide measure of work ability and it was developed at the Finnish Institute of Occupational Health in the 1980's [13].

\section{Non-disability and diagnose-specific disability retirement}

Finnish Centre for Pensions provided data on date and type of retirement and primary diagnosis for disability retirement, which was linked to the survey data using a unique personal identification number. All participants retired during January 1985 and July 2000. During the time of their retirement, statutory retirement age for municipal employees was 63 years, with the exception of special groups (e.g. pre-school teachers, bus drivers and nurses for which it was somewhat lower at 55 or 58 years) [22]. Transitioning into retirement was at that time a permanent decision, with no possibility to further participate in paid work. Besides old age retirement, employees could apply for an individual early retirement at the age of 58 years. This was usually done for reasons such as health problems, a long work career, lack of skills required in the job or working conditions, and lead to a permanent reduction in the pension level [24]. Together these two forms of retirement comprised the "non-disability retirement" group in the current study.

Disability retirement could be applied for before reaching the statutory retirement age, if the employee was due to a medically confirmed illness unable to continue working, even after periods of rehabilitation, reeducation or assistance [25]. Following the International Classification of Diseases (ICD 8-10), we classified disability retirements into the following groups: diseases of the musculoskeletal system (ICD 8-9 codes 710-739 and ICD 10 codes M00-M99), diseases of the cardiovascular system (ICD 8-9 codes 390-459 and ICD 10 codesI00-I02), mental disorders (ICD 8-9 codes 290319 and ICD 10 codes F00-F99) and all other diagnoses which included e.g. diseases of the respiratory or nervous systems and injuries or poisoning.

\section{Mobility limitation}

Mobility limitation were assessed using the latest available measure from self-reported questionnaire data collected in 1985, 1992, 1997, and 2009, described in detail elsewhere $[11,12]$. The assessment of mobility limitation included eight questions, thereof three questions on walking and moving (walking $2 \mathrm{~km}$, running $100 \mathrm{~m}$, and climbing three flights of stairs); two questions on changing and maintaining body position (squatting down and standing up again, and bending down deep e.g., to reach the feet); and three questions on carrying, moving, and handling objects (lifting and carrying heavy loads of more than $10 \mathrm{~kg}$, performing precise movements with hands and fingers e.g., potato peeling or using a screwdriver, and lifting hands over the head). The level of difficulties respondents may encounter while performing these tasks were also evaluated. If the respondent indicated having "no difficulty", the score for each individual item was coded as 0 . The corresponding score was coded as 1 for those, who indicated having at least "some difficulties". A summary score was then calculated, ranging from 0 (no difficulty in any activity) to 8 (at least some difficulties in all activities) [11, 12]. While this score does not take the severity of mobility limitation into account for the individual items, it has proven to be a reliable measure of mobility limitation [26-28].

\section{Mortality}

Mortality dates were obtained from the Finnish National Population Register between January 1981 and June 2009. Age until death or censoring on 31st July, 2009 was used as measure of survival follow-up time.

\section{Covariates}

Demographic information on respondents' age, gender and marital status (married or cohabiting vs. other) was obtained at baseline. Based on objective assessments of job characteristics at baseline, respondents were classified into the following occupational classes: blue-collar (e.g. maintenance, home care), lower white-collar (e.g. transport work, dental care), and upper white-collar (administrator, physician, teacher) [22]. The presence of baseline self-reported physician diagnosed major chronic diseases included musculoskeletal diseases (e.g. arthritis, degenerative back diseases), cardiovascular diseases (e.g. arterial hypertension, angina pectoris), metabolic disorders (e.g. diabetes, obesity), mental disorders (e.g. depression, anxiety), and cancer (benign or malignant). Lifestyle factors assessed at baseline included smoking status (never smoked / ever smoked), alcohol consumption (at least once a week / less) and physical activity during previous year (vigorous activity at least once a week / less).

\section{Statistical analyses}

Baseline descriptive statistics according to type of retirement are reported as percentages for categorical values and means and standard deviations for continuous variables.

Two models for each retirement group (non-disability, disability due to CVD, musculoskeletal diseases, mental disorders, and other diagnoses) on work ability as a predictor of old age mobility limitation were estimated. First, we modelled mobility in a Poisson regression model adjusting for age as an offset and gender. In the second model mobility was a Poisson- 
distributed outcome with adjustment made for age, gender, marital status, occupational class, chronic diseases, and lifestyle factors while mortality risk was adjusted by a random effect obtained from a simultaneous Cox regression model. In addition to the join models for both genders, we present separate models for men and women. Missing data in independent variables were assumed to be missing at random (MAR), which was accounted for in the likelihood construction for the estimation of parameters in Mplus version 7. Further details of the method can be found in Hinrichs et al. [11]. Results are presented as incident rate ratios (IRRs) with $95 \%$ confidence intervals (CIs). Percentage decrease in IRR was calculated as: $100 *(\exp (-\log (\operatorname{IRR}))-1)$. This statistic expresses risk decrease in mobility limitations for a unit increase in the workability index.

Descriptive statistics according to type of retirement were analyzed using SPSS 18.0 (IBM Corporation, Somers, NY, USA). Mplus Version 7 was used to calculate the parameters of the Poisson models [29]. CIs of incidence rates were calculated using the epiR package Version 0.9.48 in the $\mathrm{R}$ programming environment Version 2.15.2 ( $\mathrm{R}$ Foundation for Statistical Computing, Vienna, Austria), which is based on methodology described elsewhere [30].

\section{Results}

Approximately two thirds of the participants $(n=2870)$ transitioned into non-disability retirement (39\% men), while one third ( $n=1459,48 \%$ men) retired due to disability. Of these disability retirees, 714 (49\%) retired due to diseases of the musculoskeletal system, 268 (18\%) due to diseases of the circulatory system 208 (14\%) due to mental disorders, and 269 (19\%) due to all other diagnoses. Due to gender differences in type of retirement $\left(\chi^{2}=98.750, \mathrm{df}=4, p<0.001\right)$, the IRRs for old age mobility limitation by retirement groups were calculated separately for men and women. Sixty-nine percent of those who retired due to CVD and $35 \%$ of those who retired due to mental disorders were men.

Baseline characteristics, mean of work ability measured in 1985, and the IR of old age mobility limitation according to type of retirement for all participants are presented in Table 1 . Compared to non-disability retirees, those who retired due to disability were younger, more often men, married or cohabiting, blue-collar employees, suffered more frequently from major chronic illnesses, smoked and used alcohol more frequently, and were physically less active. Furthermore, those who retired due to disability reported poorer work ability in 1985 (mean $=5.8, \mathrm{sd}=2.7)$, compared to non-disability retirees (mean $=7.4$, sd $=1.6, t=19.981, \mathrm{df}=1836, p=.0 .001$ ). On average, the IR of mobility limitation for non-disability retirees was 0.45 (95\% CI $=0.44-0.46)$ and for disability retirees 0.65 (95\% $\mathrm{CI}=0.63-0.66)$. On average, the last mobility limitation was measured at age $74.1(\mathrm{sd}=6.8)$ for non-disability retirees and at age $71.2(\mathrm{sd}=7.4)$ for disability retirees $(t=12.677, \mathrm{df}=2710, p .<0.001)$. The time of mobility limitation measurement (in 1985, 1992, 1997, or 2009) by type of retirement is presented in Table 2.

Of the effective sample, those who died during the follow-up ( $n=1087)$ were older at baseline, had poorer work ability and were more likely to be men and bluecollar employees. Furthermore, they suffered more frequently from CVD, musculoskeletal and metabolic diseases, smoked more, used alcohol more frequently, and were physically less active.

IRRs and their $95 \%$ CIs for work ability predicting old age mobility limitation are presented in Table 3. A onepoint increase in the work ability score decreased the risk for having one more mobility limitation in all retirement groups, with age-adjusted risk decrease ranging between 13.6 and $4.2 \%$. The highest decrease was found for those who transitioned into non-disability retirement (IRR $=0.88,95 \% \mathrm{CI}=0.87-0.89)$. Further adjustment for chronic illnesses, lifestyle factors, and mortality risk attenuated little these risks among men and women (percentages ranging between 9.9 and 3.1).

Due to a statistically significant interaction between gender and retirement type on mobility limitation, further analyses were stratified by gender. In the nondisability retirement and disability retirement due to musculoskeletal disease groups, a one-point increase in the work ability score decreased the risk of having one more mobility limitation (13.6\% and $4.2 \%$ for men, $8.7 \%$ and $4.2 \%$ for women, respectively). Further, for men, a similar risk-decrease was found in the disability due to CVD-retirement group (IRR $=0.95$, CI $95 \%=$ $0.92-0.98)$, as well as for women in the disability due to other diagnoses-retirement group (IRR $=0.95, \mathrm{CI}$ $95 \%=0.92-0.99)$.

\section{Discussion}

This prospective large-scale study on municipal employees showed that the incidence rate of mobility limitation was higher among those who transitioned into disability retirement due to CVD, musculoskeletal and other diseases, compared to non-disability retirees. Furthermore, better work ability in midlife was associated with a decreased risk of mobility limitation among non-disability and disability retirees in all diagnose-specific groups. Allowing for main chronic illnesses, lifestyle factors and mortality risk did not markedly attenuate these associations. These findings are significant, as mobility limitation often leads to old age disability [31].

The link between better midlife work ability and lower incidence rate of old age mobility limitation among non- 
Table 1 Baseline characteristics, mobility limitation, and work ability in year 1985 according to type of retirement for all participants (percentages unless stated otherwise)

\begin{tabular}{|c|c|c|c|c|c|c|c|}
\hline & $\begin{array}{l}\text { All participants } \\
n=4329\end{array}$ & $\begin{array}{l}\text { Non-disability } \\
\text { retirement } \\
n=2870\end{array}$ & $\begin{array}{l}\text { Disability } \\
\text { retirement, } \\
\text { All causes } \\
n=1459\end{array}$ & $\begin{array}{l}\text { Disability } \\
\text { retirement, } \\
\text { Musculoskel. } \\
n=714\end{array}$ & $\begin{array}{l}\text { Disability } \\
\text { retirement, } \\
\text { Cardiovascular } \\
n=268\end{array}$ & $\begin{array}{l}\text { Disability } \\
\text { retirement, } \\
\text { Mental disor. } \\
n=208\end{array}$ & $\begin{array}{l}\text { Disability } \\
\text { retirement } \\
\text { Others } \\
n=269\end{array}$ \\
\hline Baseline age (mean, SD) & $50.1(3.4)$ & $51.1(3.5)$ & $49.5(3.0)$ & $49.5(3.1)$ & $49.5(2.9)$ & $48.9(2.9)$ & $49.5(3.1)$ \\
\hline $\begin{array}{l}\text { Married/cohabiting } \\
\text { (vs. single) }\end{array}$ & 76 & 74 & 80 & 81 & 87 & 68 & 80 \\
\hline Men & 42 & 39 & 48 & 43 & 68 & 35 & 53 \\
\hline \multicolumn{8}{|l|}{ Occupational class } \\
\hline Upper white-collars & 24 & 25 & 20 & 12 & 20 & 40 & 27 \\
\hline Lower white-collars & 36 & 39 & 28 & 31 & 24 & 37 & 25 \\
\hline Blue-collars & 40 & 35 & 51 & 57 & 56 & 23 & 48 \\
\hline Musculoskeletal disease & 37 & 33 & 47 & 56 & 38 & 35 & 40 \\
\hline Cardiovascular disease & 20 & 17 & 25 & 22 & 42 & 21 & 19 \\
\hline Metabolic disease & 6 & 5 & 8 & 7 & 8 & 9 & 7 \\
\hline Mental disorder & 2 & 1 & 3 & 2 & 0 & 8 & 3 \\
\hline Cancer & 1 & 4 & 6 & 6 & 4 & 7 & 5 \\
\hline Never smoked & 58 & 62 & 52 & 54 & 45 & 62 & 48 \\
\hline $\begin{array}{l}\text { Alcohol consumption } \\
\geq 1 \text { per week }\end{array}$ & 9 & 8 & 12 & 12 & 15 & 10 & 8 \\
\hline $\begin{array}{l}\text { Vigorous physical } \\
\text { activity } \geq 1 \\
\text { per week }\end{array}$ & 50 & 53 & 44 & 43 & 46 & 42 & 47 \\
\hline $\begin{array}{l}\text { Mobility limitation } \\
\text { (Incidence Rate, } \\
95 \% \mathrm{Cls})^{\text {a }}\end{array}$ & $0.51(0.51-0.52)$ & $0.45(0.44-0.46)$ & $0.65(0.63-0.66)$ & $0.66(0.64-0.68)$ & $0.67(0.64-0.71)$ & $0.54(0.51-0.58)$ & $0.66(0.63-0.70)$ \\
\hline $\begin{array}{l}\text { Age at last mobility } \\
\text { limitation measurement, } \\
\text { (mean, SD) }\end{array}$ & $73.1(7.1)$ & $74.1(6.8)$ & $71.2(7.4)$ & $71.5(7.4)$ & $70.4(7.7)$ & $71.8(7.3)$ & $70.5(7.2)$ \\
\hline $\begin{array}{l}\text { Work ability in } 1985 \text {, } \\
\text { (mean, SD) }\end{array}$ & $6.8(2.2)$ & $7.4(1.6)$ & $5.8(2.7)$ & $5.7(2.6)$ & $5.5(2.9)$ & $5.9(2.7)$ & $5.9(2.7)$ \\
\hline $\begin{array}{l}\text { Mortality during } \\
\text { follow-up (Incidence } \\
\text { Rate, } 95 \% \mathrm{Cls})^{\mathrm{b}}\end{array}$ & $3.26(3.07-3.46)$ & $4.04(3.68-4.43)$ & $2.87(2.66-3.10)$ & $3.42(2.97-3.95)$ & $5.52(4.58-6.65)$ & $3.31(2.53-4.34)$ & $4.81(3.95-5.87)$ \\
\hline
\end{tabular}

disability and disability retirees supports previous studies which have found vigorous occupational physical activity [11] and higher work stress [12] in midlife to be associated with old age mobility limitation. The current findings may be the result of several factors, characteristic to the concept of work ability [13] and the disablement process [4]. In addition to health and lifestyle, several factors linking midlife work ability to old age mobility limitation can be identified both among non-disability and disability retirees.

Table 2 Last mobility limitation measurement by type of retirement (percentages)

\begin{tabular}{|c|c|c|c|c|c|c|c|}
\hline $\begin{array}{l}\text { Year of mobility } \\
\text { limitation } \\
\text { measurement }\end{array}$ & $\begin{array}{l}\text { All } \\
\text { participants } \\
n=4329\end{array}$ & $\begin{array}{l}\text { Non-disability } \\
\text { retirement } \\
n=2870\end{array}$ & $\begin{array}{l}\text { Disability } \\
\text { retirement, All } \\
\text { causes } n=1459\end{array}$ & $\begin{array}{l}\text { Disability } \\
\text { retirement, } \\
\text { Musculoskel. } \\
n=714\end{array}$ & $\begin{array}{l}\text { Disability retirement, } \\
\text { Cardiovascular } \\
n=268\end{array}$ & $\begin{array}{l}\text { Disability retirement, } \\
\text { Mental disor. } \\
n=208\end{array}$ & $\begin{array}{l}\text { Disability } \\
\text { retirement } \\
\text { Others } n=269\end{array}$ \\
\hline Year 1985 & 2.5 & 2.0 & 3.3 & 1.8 & 6.7 & 2.4 & 4.5 \\
\hline Year 1992 & 10.7 & 9.4 & 13.4 & 13.3 & 14.9 & 9.1 & 15.9 \\
\hline Year 1997 & 29.3 & 28.5 & 30.8 & 31.0 & 32.1 & 28.4 & 31.2 \\
\hline Year 2009 & 57.5 & 52.1 & 52.5 & 53.9 & 46.3 & 60.1 & 48.7 \\
\hline
\end{tabular}


Table 3 Incidence rate ratios and their $95 \%$ confidence intervals for work ability as a predictor of mobility limitation. Unadjusted and mortality- and covariate-adjusted models presented for all, men and women

\begin{tabular}{|c|c|c|c|c|c|c|c|c|c|}
\hline & \multicolumn{3}{|c|}{ All $(n=4329)$} & \multicolumn{3}{|c|}{ Men $(n=1826)$} & \multicolumn{3}{|c|}{ Women $(n=2503)$} \\
\hline & \multirow[b]{2}{*}{ IRR } & \multicolumn{2}{|c|}{$95 \%$ Confidence interval } & \multirow[b]{2}{*}{ IRR } & \multicolumn{2}{|c|}{$95 \%$ Confidence interval } & \multirow[b]{2}{*}{ IRR } & \multicolumn{2}{|c|}{$95 \%$ Confidence interval } \\
\hline & & Lower & Upper & & Lower & Upper & & Lower & Upper \\
\hline \multicolumn{10}{|l|}{ Unadjusted Model ${ }^{a}$} \\
\hline Non-disability & 0.88 & 0.87 & 0.89 & 0.87 & 0.85 & 0.88 & 0.89 & 0.88 & 0.91 \\
\hline CVD & 0.94 & 0.92 & 0.96 & 0.93 & 0.91 & 0.95 & 0.97 & 0.93 & 1.01 \\
\hline Musculoskeletal & 0.95 & 0.94 & 0.96 & 0.95 & 0.93 & 0.97 & 0.95 & 0.94 & 0.97 \\
\hline Mental disorder & 0.93 & 0.90 & 0.95 & 0.90 & 0.86 & 0.94 & 0.94 & 0.91 & 0.97 \\
\hline Other & 0.96 & 0.94 & 0.97 & 0.97 & 0.94 & 0.99 & 0.94 & 0.91 & 0.97 \\
\hline \multicolumn{10}{|c|}{ Mortality and covariate adjusted Model ${ }^{\mathrm{b} c}$} \\
\hline Non-disability & 0.91 & 0.90 & 0.92 & 0.88 & 0.85 & 0.91 & 0.92 & 0.91 & 0.93 \\
\hline CVD & 0.95 & 0.93 & 0.98 & 0.95 & 0.92 & 0.98 & 0.97 & 0.93 & 1.02 \\
\hline Musculoskeletal & 0.96 & 0.95 & 0.97 & 0.96 & 0.94 & 0.99 & 0.96 & 0.94 & 0.98 \\
\hline Mental disorders & 0.96 & 0.92 & 0.99 & 0.94 & 0.88 & 1.01 & 0.97 & 0.93 & 1.01 \\
\hline Other & 0.97 & 0.95 & 0.99 & 0.98 & 0.95 & 1.02 & 0.95 & 0.92 & 0.99 \\
\hline
\end{tabular}

Bold typeface indicates effect significant at the level of $p \leq 0.05$

${ }^{a}$ Offset term for time in follow-up was used for the mobility outcome

${ }^{\mathrm{b}}$ Covariates included in the model were marital status, occupational class, chronic illnesses, and lifestyle factors

${ }^{c}$ Missing data in covariates adjusted for by maximum likelihood estimation under the assumption of missing-at-random

First, those individuals who report good work ability are likely to possess high levels of physical, psychological, and social resources in midlife [13, 15]. While these resources help employees to succeed in their jobs, they may also buffer the onset of disability [26], even among those who retire due to disability. Work-related risk factors for disability retirement are e.g. physically demanding work and low job control $[32,33]$. In the face of chronic illness and subsequent disability retirement, better midlife work ability may indicate more resources, including psychological and social, for the aging individual to fall back on. These resources may postpone the onset of mobility limitation, even among those who have retired due to e.g. musculoskeletal or cardiovascular disease. Furthermore, according to the model of the disablement process [4], the density of the social network may be an important extra-individual determinant of the onset of mobility limitation. Ways to support work ability include decreasing the physical work load, making adjustments to work-rest schedules, and introducing age-management practices, flexible working time schedules, and teamwork [34].

Second, the balance between employee resources and job demands, i.e. the absence of prolonged occupational physical and mental strain in midlife, may protect employees from old age mobility limitation [11, 12]. In fact, the positive effect of occupational activity and workengagement later in life may be reflected in old age health outcomes, such as disability or mobility [35, 36]. Especially among non-disability retirees, maintaining activity through participating in working life may help ensure mobility in old age [37]. However, it must be acknowledged that work ability is a concept which indicates the balance between employee resources and respective work demands [13]. Hence, an individual with good resources in an extremely high-strain job may report poor work ability. Vice versa, an individual with low resources in an extremely light job may report good work ability.

Finally, as work ability is partly built on employees' attitudes, motivation and values [13], it is plausible that better work ability, stemming from higher motivation for participation and positive attitudes towards work, is reflected in old age mobility. More specifically, these work-related attitudes, motivations and values may be reflected in intra-individual factors significant in terms of slowing down the disablement process [4], such as positive attitude, emotional vigor, locus of control, and cognitive adaptation to one's situation. Thus, even individuals who retire due to disability, may in terms of maintaining mobility in old age, benefit from positive midlife work attitudes and a sense of competence.

The current findings indicate some gender-differences according to type of retirement and the association between work ability and mobility limitation. Compared to women, men were more likely to retire due to CVD and less likely to retire due to other diseases, such as neurological or respiratory diseases. According to Finnish Center for Pensions statistics men were more likely to retire due to disability caused by CVD compared to women $(9.1 \%$ vs. $4.5 \%$, out of all those retired due to disability in 2013) [19]. Furthermore, better work ability 
decreased the risk for old age mobility limitation among men who retired due to CVD and among women, who retired due to other diseases, such as neurological and respiratory diseases. These findings may indicate that for men, old age mobility limitation may be linked with work-related factors, particularly poor work ability in middle age. The association between work strain in midlife, similar to poor work ability, and negative health outcomes in old age is stronger for men compared to women [38].

Finally, while better work ability decreased the risk for old age mobility limitation among those who retired due to mental disorders in the combined model for men and women, this association was not found in the models stratified by gender. This finding may be caused by the low number of participants in this disability retirement group $(n=208$, men $n=72)$. The similar type of association between work ability and mobility limitation for all participants and in the gender-stratified models, along with the wider CIs, indicate that these findings may be power-related. Besides the low prevalence of mobility limitation in this disability retirement group and the low number of individuals, there may be other factors explaining this finding. Notably, the majority of those who retired due to mental diseases worked in higher white-collar jobs. This may not only explain the relatively low mobility limitation incidence $(\mathrm{IR}=0.54, \mathrm{CI}=$ 0.51-0.58), compared to other disability retirement groups, but also affect the role of work ability on old age mobility limitation.

This study was based on a large-scale populationbased dataset consisting of a wide variety of municipal occupations, with both genders represented. The long follow-up time allowed us to explore midlife work ability in association with old age mobility limitation. Common to all follow-up studies, there are some limitations that need to be addressed. First, while self-reported mobility limitation and work ability were measured with widely accepted and validated scales [26-28, 39], some selfreport bias might have influenced the results. Retirement and mortality data were retrieved from national registers. Second, as mobility limitation was not available at baseline, we cannot rule out the possibility that some participants had some mobility limitation at baseline. However, because all participants were occupationally active at baseline and were likely to have only a minimal level on mobility limitation at that time, we do not believe that this influenced the results markedly. Also, controlling for age at last mobility limitation measurement changed little the regression results. Third, common to corresponding long-term prospective designs, this study may be influenced by selective dropout. The 'healthy worker survivor effect' is an ongoing process where those who stay in a specific occupation tend to be healthier than those who exit employment [40]. As a result of this potential selection in the data, our results may be an underestimation of the incidence of mobility limitation in old age. Finally, participants of the current study were occupationally active municipal sector employees, which should be considered when generalizing the present results on a population level.

\section{Conclusions}

Taken together, the current findings indicate that the balance between employee's resources and work demands in midlife has independent, long-term effects on old age mobility, as better midlife work ability may protect from old age mobility limitation among those who retire due to non-disability and disability. Promoting work ability in midlife may lead to more independent, active aging, regardless of type of retirement.

\section{Abbreviations}

Cl: 95 \% confidence interval; CVD: cardiovascular disease; FLAME: Finnish longitudinal study of municipal employees; ICD: international classification of diseases; IRR: incidence rate ratio; WAl: work ability index.

\section{Competing interests}

The authors declare that they have no competing interests.

\section{Authors' contributions}

$J$ I, C-HN, JS, and TR: conception and design of FLAME. JS, MB. von B, and ME. von $B$ : data collection and data management. ME. von B, MB. von B, TT, TH, $J K$, and TR: Work ability, retirement and mobility limitation study design. TT and $M$ von $B$ : data analysis. ME. von B, MB. von B, TH, JK, TR, and C-HN: data interpretation. ME. von B: drafting the manuscript. All authors critically revised the manuscript and gave final approval of the version to be published.

\section{Acknowledgements}

MEvB was funded by the Academy of Finland (grant n:o 250681). MBvB was funded by the Academy of Finland (grant n:o 257239). JK was funded by the Academy of Finland (grant number 250385). TT was funded by the Academy of Finland (grant n:o 286536). The Local Government Pension Institution contributed to the gathering of the data.

\section{Author details}

${ }^{1}$ Gerontology Research Center and Department of Health Sciences, University of Jyväskylä, PO Box 35, Jyväskylä, Finland. ${ }^{2}$ Folkhälsan Research Center, Helsinki, Finland. ${ }^{3}$ Chronic Disease Prevention Unit, National Institute for Health and Welfare, Helsinki, Finland. ${ }^{4}$ School of Health Care and Social Work, Seinäjoki University of Applied Sciences, Seinäjoki, Finland. ${ }^{5}$ Division of Sports and Exercise Medicine, Department of Sport, Exercise and Health, University of Basel, Basel, Switzerland. ${ }^{6}$ Finnish Institute of Occupational Health, Helsinki, Finland. ${ }^{7}$ Gerontology Research Center and School of Health Sciences, University of Tampere, Tampere, Finland. ${ }^{8}$ University of Eastern Finland, Kuopio, Finland

Received: 14 September 2015 Accepted: 8 February 2016

Published online: 16 February 2016

\section{References}

1. Satariano WA, Guralnik JM, Jackson RJ, Marottoli RA, Phelan EA, Prohaska TR. Mobility and aging: New directions for public health action. Am J Public Health. 2012;102:1508-15.

2. Hirvensalo M, Rantanen T, Heikkinen E. Mobility Difficulties and Physical Activity as Predictors of Mortality and Loss of Independence in the Community-Living Older Population. J Am Geriatr Soc. 2000;48:493-8.

3. von Bonsdorff M, Rantanen T, Laukkanen P, Suutama T, Heikkinen E. Mobility limitations and cognitive deficits as predictors of institutionalization among community-dwelling older people. Gerontology. 2006:52:359-65. 
4. Verbrugge LM, Jette AM. The disablement process. Soc Sci Med. 1994;38:1-14.

5. Guralnik JM, LaCroix AZ, Abbott RD, Berkman LF, Satterfield S, Evans DA, et al. Maintaining mobility in late life. I. Demographic characteristics and chronic conditions. Am J Epidemiol. 1993;137:845-57.

6. Freedman VA, Martin LG, Schoeni RF. Recent trends in disability and functioning among older adults in the United States. JAMA. 2002;288:3137-46.

7. Oldridge NB, Stump TE. Heart disease, comorbidity, and activity limitation in community-dwelling elderly. Eur J Cardiovasc Prev Rehabil. 2004;11:427-34.

8. Shumway-Cook A, Ciol MA, Yorkston KM, Hoffman JM, Chan L. Mobility limitations in the Medicare population: Prevalence and sociodemographic and clinical correlates. J Am Geriatr Soc. 2005;53:1217-21.

9. McAuley E, Konopack JF, Morris KS, Motl RW, Hu L, Doerksen SE, et al. Physical activity and functional limitations in older women: influence of self-efficacy. J Gerontol B Psychol Sci Soc Sci. 2006;61:P270-277.

10. Brown CJ, Flood KL. Mobility Limitation in the Older Patient: A Clinical Review. JAMA. 2013;310:1168-77

11. Hinrichs T, von Bonsdorff MB, Törmäkangas T, von Bonsdorff ME, Kulmala J, Seitsamo J, et al. Inverse effects of midlife occupational and leisure time physical activity on mobility in old age - a 28-year prospective follow-up study. J Am Geriatr Soc. 2014;62:812-20.

12. Kulmala J, Hinrichs $T$, von Bonsdorff MB, von Bonsdorff ME, Nygård CH, Klockars M, et al. Work-related Stress in Midlife Is Associated with Higher Number of Mobility Limitation in Old Age - Results from the FLAME Study. Age. 2014;36:9722

13. IImarinen J. Work ability - a comprehensive concept for occupational health research and prevention. Scand J Work Environ Health. 2009;35:1-5.

14. von Bonsdorff MB, Seitsamo J, Ilmarinen J, Nygård CH, von Bonsdorff ME, Rantanen T. Work ability in midlife as a predictor of mortality and disability in later life: A 28-year prospective follow-up study. CMAJ. 2011;183:E235-42.

15. Alavinia SM, Burdorf A. Unemployment and retirement and ill-health: a cross-sectional analysis cross European countries. Determinants of work ability and its predictive value for disability. Int Arch Occup Environ Health. 2008;82:39-45

16. Ahlstrom L, Grimby-Ekman A, Hagberg M, Dellve L. The work ability index and single-item question: associations with sick leave, symptoms, and health - a prospective study of women on long-term sick leave. Scand J Work Environ Health. 2010;36:404-12.

17. OECD. Sickness, disability and work: Breaking the barriers; A synthesis of findings across OECD countries. OECD Publishing. http://ec.europa.eu/ health/mental_health/eu_compass/reports_studies/disability_synthesis_ 2010_en.pdf. [Accessed August 18th, 2015].

18. Björkenstam C, Alexanderson K, Björkenstam E, Lindholm C, Mittendorfer-Rutz E. Diagnosis-specific disability pension and risk of all-cause and cause-specific mortality - a cohort study of 4.9 million inhabitants in Sweden. BMC Public Health. 2014:14:1247.

19. Finnish Centre for Pensions. Pensioners and insured in Finland. Official Statistics. Helsinki: Finnish Centre for Pensions and Keva. 2013. http://www. etk.fi/fi/gateway/PTARGS_0_2712_459_440_3034_43/http\%3B/content.etk. fi\%3B7087/publishedcontent/publish/etkfi/fi/julkaisut/tilastojulkaisut/ tilastovuosikirjat/suomen_tyoelakkeensaajat_ja_vakuutetut_2013_7.pdf. [Accessed August 3rd 2015].

20. Wallman T, Wedel H, Johansson S, Rosengren A, Eriksson H, Welin L, et al. The prognosis for individuals on disability retirement An 18-year mortality follow-up study of 6887 men and women sampled from the general population. BMC Public Health. 2006:6:103.

21. Gjesdal S, Svednerg P, Hagberg J, Alexanderson K. Mortality among disability pensioners in Norway and Sweden 1990-96: Comparative prospective cohort study. Scand J Public Health. 2009;37:168-75.

22. Ilmarinen J, Tuomi K, Eskelinen L, Nygård CH, Huuhtanen P, Klockars M. Background and objectives of the Finnish research project on aging workers in municipal occupations. Scand J Work Environ Health. 1991;17 Suppl 1:7-11.

23. Tuomi K, Ilmarinen J, Eskelinen L, Järvinen E, Toikkanen J, Klockars M. Prevalence and incidence rates of diseases and work ability in different work categories of municipal occupations. Scand J Work Environ Health. 1991;17 Suppl 1:67-74

24. Hytti $\mathrm{H}$. Early exit from the labour market thorough unemployment pathway in Finland. Working Papers 2002:2. Helsinki: Central Pension institute; 2002

25. Finnish Centre for Pensions. Pensioners and insured in Finland 2011. Official Statistics. Helsinki: Finnish Centre for Pensions and Keva. http://www.etk.fi/fi/
gateway/PTARGS_0_2712_459_440_3034_43/http\%3B/content.etk. fi\%3B7087/publishedcontent/publish/etkfi/fi/julkaisut/tilastojulkaisut/ tilastovuosikirjat/suomen_tyoelakkeensaajat_ja_vakuutetut_2011_7.pdf. [Accessed August 2nd, 2015].

26. Lawrence $\mathrm{RH}$, Jette $\mathrm{AM}$. Disentangling the disablement process. J Gerontol B: Psychol Sci Soc Sci. 1996;51B:S173-82.

27. Netuveli G, Wiggins RD, Hildon Z, Montgomery SM, Blane D. Quality of life at older ages: evidence from the English longitudinal study of aging (wave 1). J Epidemiol Community Health. 2006;60:357-63.

28. Lee CT, Yeh CJ, Lee MC, Lin HS, Chen VC, Hsieh MH, et al. Leisure activity, mobility limitation and stress as modifiable risk factors for depressive symptoms in the elderly: Results of a national longitudinal study. Arch Gerontol Geriatr. 2012:54:E221-9.

29. Muthén LK, Muthén BO. Mplus user's guide (6th ed.). Los Angeles, CA: Muthén \& Muthén; 1998-2010.

30. Collett D. Modelling Binary Data. Boca Raton: Chapman \& Hall/CRC; 1999.

31. Harttgen $K$, Kowal P, Strulik H, Chatterji S, Vollmer S. Patterns of frailty in older adults: comparing results from higher and lower income countries using the Survey of Health, Ageing and Retirement in Europe (SHARE) and the Study on Global AGEing and Adult Health. PlosOne. 2013;13:e75847. doi 10.1371/journal.pone.0075847.

32. Hagen KB, Tambs K, Bjerkedal T. A prospective cohort study of risk factors for disability retirement because of back pain in the general working population. Spine. 2002;27:1790-6.

33. Alavinia SM, De Boer AGEM, Van Duivenbooden JC, Frings-Dresen MHW, Burdorf A. Determinants of work ability and its predictive value for disability. Occup Med. 2009;59:32-7.

34. Ilmarinen J, Rantanen J. Promotion of work ability during ageing. Am J Indust Med Suppl. 1999;1:21-3.

35. Wallman T, Burell G, Kullman S, Svärdsudd K. Health care utilization before and after retirement due to illness. A 13-year population-based follow-up study of prematurely retired men and referents from the general population. Scand J Health Care. 2004:22:95-100.

36. Wickrama KAS, O'Neil CW, Kwag KH, Lee TK. Is working later in life good or bad for health? An investigation of multiple health outcomes. J Gerontol B: Psychol Sci Soc Sci. 2013;68:807-15.

37. Hinterlong JE, Morrow-Howell N, Rozario PA. Productive engagement and late life physical and mental health findings from a nationally representative panel study. Res Aging. 2007;29:348-70.

38. von Bonsdorff MB, Seitsamo J, von Bonsdorff ME, Ilmarinen J, Nygård CH, Rantanen T. Job strain among manual and non-manual employees as a determinant of mortality: A 28-year population-based follow-up. BMJ Open. 2012;2(2):e000860

39. Eskelinen L, Toikkanen J, Tuomi K, Mauno I, Nygård CH, Klockars M, et al. Work-related stress symptoms of ageing employees in municipal occupations. Scand J Work Environ Health. 1991;17:87-93.

40. Wunsch G, Duchene J, Thiltges E, Salhi M. Socio-economic differences in mortality. A life course approach. Eur J Popul. 1996:12:167-85.

\section{Submit your next manuscript to BioMed Central and we will help you at every step:}

- We accept pre-submission inquiries

- Our selector tool helps you to find the most relevant journal

- We provide round the clock customer support

- Convenient online submission

- Thorough peer review

- Inclusion in PubMed and all major indexing services

- Maximum visibility for your research

Submit your manuscript at www.biomedcentral.com/submit 